\title{
How Teachers Evolve Their Formative Assessment Practices When Digital Tools Are Involved in the Classroom
}

\author{
Monica Panero $^{1} \cdot$ Gilles Aldon $^{1}$
}

Published online: 8 February 2016

(C) Springer International Publishing 2016

\begin{abstract}
Formative assessment is a process that can inform both teachers and students of their understanding of knowledge at stake. Technology can enable data about student understanding to be collected, organised and shared in novel ways. The FaSMEd project aims to study how technology can play an effective role within a formative assessment process. This article presents a case study that allows us to understand better how a teacher processes data from student use of technology (e.g., tablets, a student response system, interactive whiteboards) and how he uses it to inform his teaching. Our observations in a grade 9 tablet-using classroom show that technology can be considered as an element of the classroom milieu facilitating the process of formative assessment. Both the teacher and the students took advantage of the interpretation of data: the teacher modified his teaching regarding students' responses, while the students improved their learning in response to the teacher's feedback.
\end{abstract}

Keywords Formative assessment · Secondary education · Technology

\section{Introduction}

This article reports on an on-going research project we are carrying out within a wider European project, called FaSMEd (Improving progress for lower achievers through Formative Assessment in Science and Mathematics Education). The research aim of this project is to investigate the role of technologically enhanced formative assessment

Monica Panero

monica.panero@ens-lyon.fr

Gilles Aldon

gilles.aldon@ens-lyon.fr

1 Ecole Normale Supérieure de Lyon, Institut Français de l'Education, 15 parvis René-Descartes BP 7000, 69342 Lyon cedex 07, France 
methods in raising the attainment levels of low-achieving students. Discussions about formative assessment (Taras 2012) identify two categories of definitions: the first based on product assessment (Black et al. 2003) and the second on process assessment (Black and Wiliam 2009). In the FaSMEd project, we have adopted the second type of formative assessment, where learning and assessing are deeply linked. Feedback is at the core of either summative or formative assessment, but feedback in formative assessment is used to enhance the teaching and learning process. In this sense, formative assessment becomes a teaching method where:

evidence about student achievement is elicited, interpreted, and used by teachers, learners, or their peers, to make decisions about the next steps in instruction that are likely to be better, or better founded, than the decisions they would have taken in the absence of the evidence that was elicited. (Black and Wiliam 2009, p. 7)

A digital environment that improves connectivity and feedback can assist teachers in making more timely formative interpretations. Technologies that support knowledge construction through connectivity in the classroom have been widely studied in mathematics education (Stroup et al. 2002; Pape et al. 2013) often linked to the design of specific software as it occurred for example in the Group Scribble project (Looi and Chen 2010). Furthermore, other research has investigated the contribution of technology to the teaching and learning of mathematics with a particular attention to the cognitive aspects and knowledge building (Scardamalia and Bereiter 2006) or to new possible didactic approaches (Aldon et al. 2008). Moreover, as Borman and Sleigh (2011) remark, students can become significantly engaged in non-summative marking systems, provided they perceive what they are learning as useful and important. Our project relies on the hypothesis that creating such a digital environment has the potential to amplify the quality of the assessment of student achievement (Hattie 2009). Moreover, both teachers and students have access to the collected data for real-time interpretation and further use.

In the FaSMEd project, our aim is to combine the two aspects of formative assessment and connectivity in the classroom, in order to investigate how formative assessment can be enhanced by technology. More precisely, in this article, we focus on the information and communication potentialities of technology. In particular, during the second year of the project, we followed the 'school life' of one connected classroom, where every student had been provided with a tablet (Microsoft Surface) and used it for all subjects: we refer to this environment as a 'tablet classroom'.

We both observed some lessons and read reports written by the team of teachers of the tablet classroom. We have experienced the effect of tablets on the reality of the classroom, where the teacher has to develop several orchestration skills to cope with the features of the work in the class that deeply changes (e.g., the status of written responses or the organisation of the work in groups). Observing the classroom, we witnessed what Walling (2014) describes:

In the emerging world of a tablet classroom the teacher is likely to be a principal learning designer. [...] In an ideal educational environment, of course, teachers would have adequate training prior to being thrown into a tablet classroom. Most often this ideal is not realized, and training is sketchy at best. Consequently, 
effective teachers draw on both art and science to craft teaching and learning for their students, whether collectively or individually. If we compare effective teachers to jazz musicians, they must be exemplary players, more than merely technically competent. They know when to follow the score (the curriculum) and when to improvise. (pp. 26-27)

Tablets support, accompany and sometimes replace students' notebooks and the paper-and-pencil environment. On the technical side, several competences are needed by the teacher to make the lesson develop in a natural way for students. On the didactic side, the usual tasks have to be adapted and new tasks can be designed and proposed. Moreover, the way of exploiting such tasks in the classroom can change as a result of the possibilities offered by connected classroom technologies. Nonetheless, the challenges are great. Different studies have highlighted that connected classroom technologies have increased the complexity of the teacher's role with respect to orchestrating the lesson (Clark-Wilson 2010). As a 'conductor-of-performances', in fact, the teacher is responsible for choosing and sequencing the material to be performed, interpreting the performance and guiding it toward its desired forms (Roschelle and Pea 2002).

In our research, we left the responsibility for designing their lessons to the teachers themselves, being at their disposal for discussion and advice if they wished. Then we observed and analysed some lessons in order to discuss them with the involved teachers at a later time. These lessons were chosen not for their topic, but rather because they were representative of different stages of the experimentation during the school year. This process generates successive cycles of design, observation, analysis and redesign of classroom sequences (Swan 2014). The resources for the classroom, designed and redesigned through this process, inform the production of a toolkit, which is a set of curriculum materials and methods for teachers to support the development of practice.

In line with the project's purposes, we carried out this case study in order to understand the possible formative assessment practices involving technology that could be introduced efficiently in classrooms. Such practices may not involve just multiple-choice tests (Lawson 1999), but enhance the communication between students and teacher. More precisely, our study is focused on a grade 9 tablet classroom, where the software NetSupport School ${ }^{1}$ was used as the main connected classroom technology for classroom instruction, orchestration, monitoring and management. In particular, the functionalities of the integrated student response system were tested. Our observations served as windows on the classroom at three occasions during the school year, which were short but significant in the development of the project: at the beginning of the year (in November), in the middle of the year (in February) and at the end of the year (in April). In this article, we will try to respond to the following questions: how does the teacher process data from students using the available technology (i.e., tablets, NetSupport School, student response system, IWB) and how does he use such data to inform his teaching?

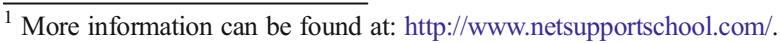




\section{Theoretical Framework}

When technology is present in the classroom as a learning tool, we can describe the resulting situation with reference to the theory of didactical situations (Brousseau 1997). The teacher creates a milieu the students have to contend with and modifies it depending on the student-milieu interaction. According to Brousseau (1997), "Within a situation of action, everything that acts on the student or that she [the student] acts on is called the 'milieu'" (p. 9). More precisely, Brousseau models a didactic situation as a game played by the teacher and the students within an environment "the playground in which (and against which) the players play is called the milieu; the milieu is thought of, designed, organised and observed by the teacher and when students play the game, the milieu responds to the students' actions" (Aldon 2014, p. 321). In our study, we consider the technology as a part of the milieu that plays a fundamental role in providing information for the students. Brousseau (1997) further specifies the teacher's role, by declaring that, "Teaching is the devolution to the student of an a-didactical, appropriate situation; learning is the student's adaptation to this situation" (p. 56). In a complementary way, the process of institutionalisation corresponds to the phase in which the teacher "defines the relationships that can be allowed between the student's 'free' behaviour or production and the cultural or scientific knowledge and the didactical project; she [the teacher] provides a way of 'reading' these activities and gives them a status" (p. 56).

In the presence of technology, the role of the teacher evolves when managing the essential task of orchestrating its use in the classroom. Indeed, each student working with a particular technology develops his/her own schemes of use with respect to it, through a process that is called instrumental genesis (Rabardel 1995). This model explains the appropriation of artefacts and their transformation in a two-way movement of instrumentation, when the artefact changes the subject's behaviour relative to a given task, and instrumentalisation, when the subject shapes the artefact for his/her own use. The result of this genesis is what is called an instrument, which consists of the artefact plus certain schemes of use (Artigue 2002).

For each student, as well as for the teacher, the technology changes from a simple artefact to become an instrument through this two-way movement from the artefact to the user and from the user to the artefact, but the duration of the instrumental genesis can be very different from student to student. Therefore, working on the same situation, students can be in different phases of their individual instrumental genesis. In the context of a tablet classroom, where each user is appropriating his/her own tablet, the orchestration of all the different schemes of use - which occur at different levels - is a crucial task for the teacher. At the same time, the teacher is also confronted by his/her own instrumental genesis regarding the connected classroom technologies. With this concern, Trouche (2004) speaks of instrumental orchestration to indicate didactic configurations involving the artefacts available in the environment. In the case of a tablet classroom, where all the tablets are networked and reachable by the teacher, this framework is particularly appropriate to describe and interpret the teacher's use of the chosen connected classroom technology.

Feedback from technology is useful for both the student and the teacher. Students can use it to improve their performance when faced with questions or to change their strategies in the resolution of a problem. Nonetheless, considering the technology as a 
part of the milieu, the feedback informs the student and its problematic characteristic becomes a new element that can enrich the milieu and foster knowledge construction. This surely entails a moment of difficulty for students, but the way in which the student copes with it can actually inform her or him - and the teacher as well - about the understanding of a particular concept. The teacher, in turn, can use this feedback to gain an overview of the classroom's state of learning, to detect problematic notions and to identify which students have more difficulties with a particular concept, and then to adapt his/her didactic strategy. It is in such conditions that assessment becomes formative and can efficiently contribute to the students' learning.

When observing a lesson, we are interested in those moments in which the teacher collects data and draws on it in order to determine the didactic technique. Starting from the lesson plans, all these local variations contribute to shape the teacher's actual practice in the classroom.

\section{Context of the Study and Methodology}

In the observed grade nine tablet classroom, each student had been equipped with and had responsibility for a specific tablet during school hours, using it for all the subjects (Fig. 1). Personal use of tablets in the classroom encouraged the students to appropriate them and allowed teachers to follow the progress of each student more directly.

In this study, as well as in the course of the whole project, we intended to support teachers to use the tools they were already using and to introduce other supporting tools if and where necessary. This decision allowed teachers to collect and use feedback from students in a way that is, as far as possible, independent of the teacher's and the students' level of familiarity with the tools. Our aim was to gain insight into the way

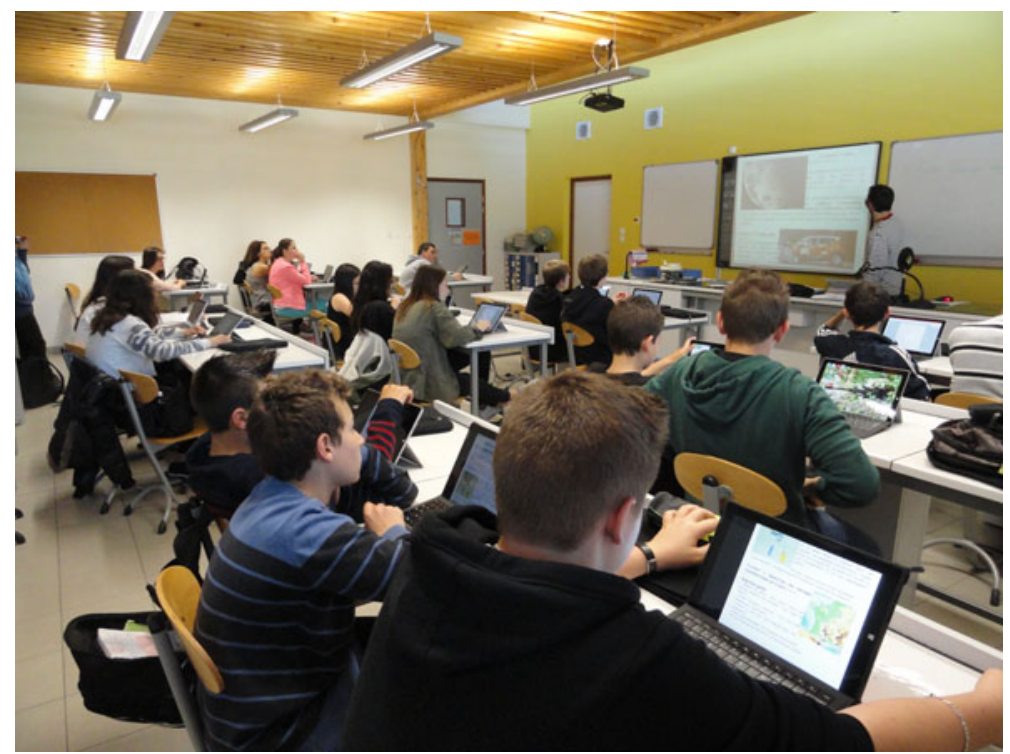

Fig. 1 The configuration of the tablets in the classroom 
teachers could adapt the technological tools available in the classroom for formative assessment purposes.

The observed teacher ( $\mathrm{T}$ in the following) decided to exploit the student response system offered by the network of tablets that he was already using in the classroom. In such a context, the arrangement of the technological environment and the teacher's exploitation of it can be described within the framework of instrumental orchestration. T networked all of the tablets in the classroom, so that each tablet would communicate with the central system. He acted directly on NetSupport School to communicate with all the students. He used the IWB as a common screen to collect all of the data sent by the students. In this particular environment, he exploited a functionality of NetSupport School that works as a student response system. So he sent a question to each student, typing and hiding the correct answer; then he got an elaboration of the set of answers typed by each student on his/her own tablet, compared with the correct one (so they appeared in red or green).

The particular orchestration chosen by $\mathrm{T}$ provided him with data that could potentially inform his teaching and produce other means of exploiting the arranged didactic configuration, that he perhaps decided on the spot, during the lesson. It is interesting also to notice that, in this technological environment, $\mathrm{T}$ wanted to maintain a written record of the work done during the lesson. Instrumental orchestration is not limited to the use of digital artefacts but combines all suitable artefacts leading to a given goal, digital tools as well as paper and pencil (see Fig. 2).

In order to contextualise our three observations during the school year, the teachers of the tablet classrooms gave us access to the documents and the reports they had shared within their groups. For instance, we could read the school-year logbook, where all the teachers shared important notes from their lessons about their technical and pedagogical use of the tablets in the classroom. In addition, we met with them outside of lesson time in order to discuss our analysis results and reflect on strong and weak points of the use of tablets in the classroom.

We talked about formative assessment strategies with technology with all of the teachers, but in particular, we worked with the mathematics teacher T to collect data to feed into the analyses of the FaSMEd project. We chose to present the case of this

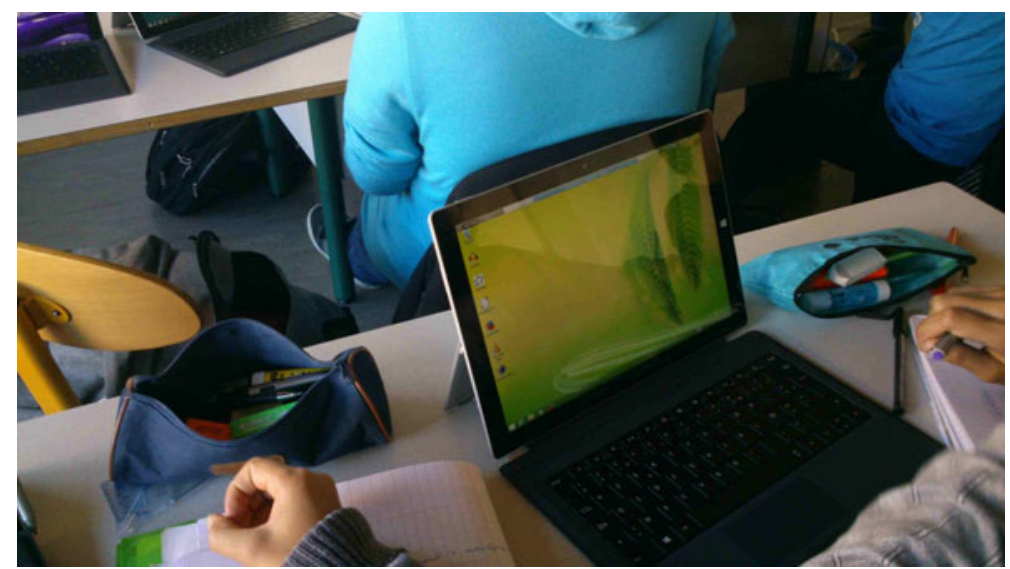

Fig. 2 Instrumental orchestration combines digital and more traditional tools 
teacher among all the observations carried out in the project because, differently from other tablet classrooms, in this one the teacher tried to integrate the use of tablets for teaching every mathematical concept throughout all of the school year, and not only to see the effects in relation to some selected tasks. This allowed us to investigate the evolution of his practices in the classroom over a long period of time. For this purpose, we used the methods that we carried out in all our FaSMEd observations.

Before the observations, we asked $\mathrm{T}$ to record some important points to reflect upon, including: prerequisites and objectives of the lesson, organisation of the classroom and of the work, and expected difficulties. We undertook this methodological choice in order to identify the learning goals the teacher wanted the students to achieve in each lesson, to reconstruct his lesson plan and his expected reactions to cope with students' possible difficulties, and to compare them with respect to his actual decisions in the classroom. These notes supported our analysis of the decisions the teacher undertook in response to the elicited evidence of student understanding.

As already mentioned, we visited the mathematics classroom three times during the school year as observers, without participating in the lesson design and implementation. Collected data during the classroom observations included audio-recording of whole sequences, some videos and photographs. In particular, we focused on the teacher's use of the network of tablets in relation to other technological tools in the classroom (i.e., the interactive whiteboard). After each observation, we met with the teacher to discuss what had happened in the classroom, possible exploitations of collected data and possible modifications in the teacher's lesson design.

In the next section, aspects of these data are analysed, according to the theoretical framework described in section 2 .

\section{Data Analysis}

In this section, we present our analysis of three lessons observed during the school year. We consider them as short but significant episodes in the development of the project: at the beginning of the year (in November 2014), in the middle of the year (in February 2015) and at the end of the year (in April 2015).

The first occasion of analysis is based on an observation that took place in November, 2014, at the very beginning of the use of tablets in the classroom. The observed mathematics lesson was about the geometry of the circle. The teacher tested the student response system for the first time. The second occasion chosen for analysis comes from the observation of February, 2015. The NetSupport School was used not only to send questions and collect answers, but also to capture images of the students' work and share them within the class. This lesson is an introduction to probability. The third occasion that we analysed involves a lesson about linear functions, observed in April, 2015, where the teacher refined his use of technology with a greater focus on the formative assessment of the students.

The analysis of these three observations is structured around the teacher's orchestration choices. How does he organise the students' use of tablets? How does he co-ordinate the students' work? Which functionalities of the technology available to the classroom are exploited and how? What are the influences on the students' milieu? 
Following a discussion of these questions, we will try to answer our two research questions about formative assessment: how does the teacher process data from student use of technology and how does he use it to inform his teaching?

\section{First Classroom Observation (November, 2014)}

$\mathrm{T}$ proposed two geometrical problems that required that the students determine the length of a chord, given the radius of the circle and the angle subtended by it at the centre. In the first case, the radius is $3 \mathrm{~cm}$ long and the angle is $60^{\circ}$. Students worked individually on their own tablet, but they could discuss their work with classmates. The teacher reminded the students of all of the possible forms of support they could draw upon to solve the problem:

$1 \mathrm{~T}$ : You have many possibilities: you can draw the figures by hand in real dimensions, you can do some calculation [...] you can also draw the figure in real dimensions with GeoGebra if you want. Do whatever you want. I give you, it's 27 , at 32 I want there to be some answers [...] that everyone has an answer to propose, right or wrong it doesn't matter, but in 5 min I want everyone to have an answer to propose with a written argument. (Translated from French by the authors)

With his words, the teacher devolved the problem to the students. He left them to cope with a milieu that encompassed their geometrical knowledge, the given geometrical problem and the tools at their disposal. He gave them complete freedom to choose their resolution strategy ("Do whatever you want"), but he specified that a justification was needed (one "with a written argument") and not simply "an answer to propose". We find his clarification about the allowed answers extremely interesting: "right or wrong, it doesn't matter". He encouraged the students to propose their solutions and to be prepared to defend it. Following this, the students worked on the task alone or in pairs. There could be interaction with the tablet if they drew and explored the figure with GeoGebra. Thus, a priori, $\mathrm{T}$ permitted the work on the tablet and using paper and pencil as well, as the students preferred. This is another important element of orchestration that is explicitly declared in the classroom. However, in fact, few students opened GeoGebra. They generally preferred to work in their notebooks (Fig. 3).

After a while, T sent the question "What is the length of the chord?" to all the students' tablets through the NetSupport School network. He asked students to submit their results individually by typing the value of the length of the chord directly on their tablet. The answers were evaluated by the system. In that moment, all the students interacted with the tablet and the attention in the classroom was focused on the IWB that displayed the common grid with all of the students' answers collated. We saw the students use the tablet mainly as a means of communication. T reviewed the exercise on the IWB, asking students to provide reasons for all the steps. This first problem was useful for the teacher to introduce the task to the students and also to test the student response system. The students' milieu was enriched by the resolution and the correction of the first problem. 


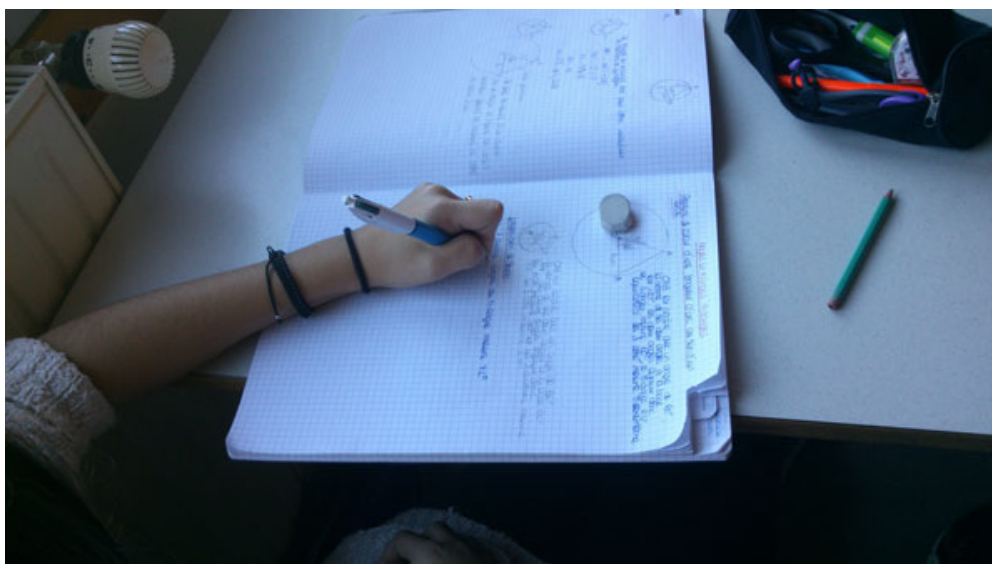

Fig. 3 A student's exploration in her notebook

Afterwards, the teacher invited the students to focus on a second problem. The geometrical situation was similar to the previous one, with the radius of the circle being $3 \mathrm{~cm}$, but this time the angle at the centre was $36^{\circ}$. The task was the same: to find the length of the chord. T suggested that the students use what they know about rightangled triangles (i.e., the relation between the legs and hypotenuse, in terms of sine and cosine) and to try to identify a right-angled triangle in the figure.

Following a different line of reasoning, a student (we will call him Student1) finished very quickly and proposed his solution to the teacher (see Fig. 4). It was an incorrect argument, but $\mathrm{T}$ showed it to the class in order to discuss it.

2 T: I highlight Student1's remark, on which we'll stop in 2 min to discuss. Let's simply note it, [...] without judging it for the moment. So, note Student1's

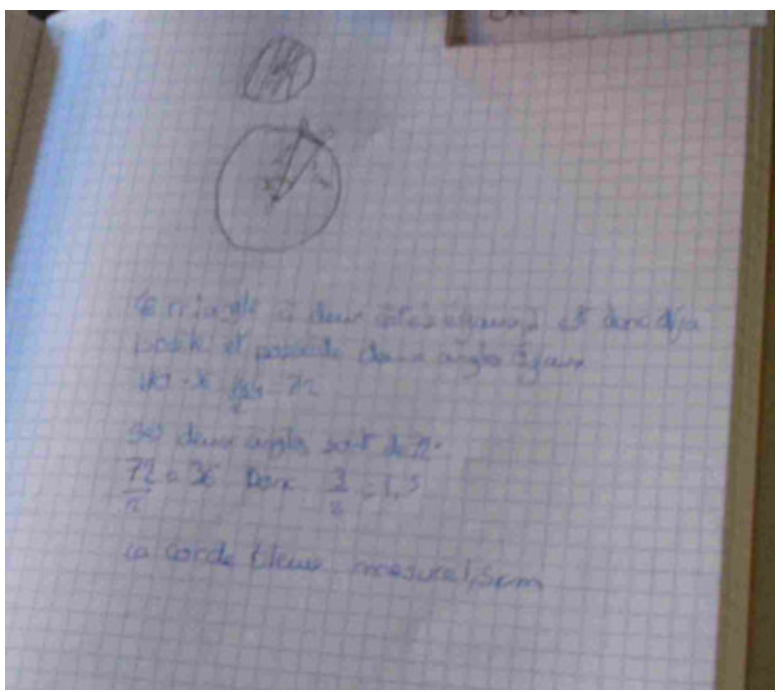

Fig. 4 Student1's solution: The triangle has two equal sides and is therefore isosceles and has two equal angles. $/ 180-36=144 / 2=72 /$ Its two angles are $72^{\circ} / 72 / 2=36$ and so $3 / 2=1.5 /$ The blue chord is $1.5 \mathrm{~cm}$ 
proposal. He proposed something that would be so practical! [...] So, he said this [angle at the centre] is 36, so those two [angles at the base] are 72.36 is half of 72 , so $A B$ is half of 3 .

\section{Students: Uh!}

$4 \mathrm{~T}$ : [...] Student2, is your conclusion different from that of Student1 or did you get the same result? You did get a result, didn't you?

5 Student2: Yes.

6 T: So, I'm going to take Student1, then you will tell me the way you concluded.

7 Student2: It isn't right.

8 T: I don't know. If it isn't right, you will tell me why it isn't right. The other two angles of the triangle are $72^{\circ}, 36$ is half of 72 , then $\mathrm{AB}$ is half of $\mathrm{OB}$.

9 Student3: But how do you know it is half? You don't see it there!

$10 \mathrm{~T}$ : I agree with you, this is a question we should ask Student1. Nonetheless, what I ask you with respect to this is what is the mathematical notion that [...] Student1 presupposes when he does so. What mathematical property is he using? What is he using in mathematics? [...] I'm going to ask you the question on the tablet. You are to answer on the tablet.

In the above, T chose the solution of a student and rewrote it on the IWB, in order to share it with the whole class. He specified that his intention was not to judge Student1's proposal ("Let's simply note it without judging it", turn 2) but to discuss it. His choice is particularly interesting, because Student1's proposal and solution are wrong, even if the reasoning began correctly with the calculation of the size of the angles. We point out that discussing a classmate's proposal could be an effective technique to foster formative assessment in the classroom. Every student has the possibility to compare his/her production with the one that is presented and the teacher can respond by using other students' reactions. In this case, the fact that several students reacted with an exclamation of surprise (turn 3) to Student1's wrong solution informed $\mathrm{T}$ about the direction he had to give to his intervention.

Orchestrating the work of different students was his explicit intention (turns 4-8). Even though a student, probably a high achiever, noticed that there was something wrong with the proposed solution (turn 9), T quickly agreed with him ("I agree with you, this is a question we should ask to Student1", turn 10), but he continued by discussing Student1's argument. In particular, he wanted to focus students' attentions on the mathematical property that underpins Student1's proposal. His aim indeed was not simply to lead the students to reject the proposal. He wanted to be sure that the students got to understand the mathematical reason for which it had to be rejected. Then, T chose to ask the question via tablet, through the student response system.

While the students were sending their answers and the system was assembling them, the teacher made an oral survey. This choice allowed him to make a comparison with 
the electronically collected data. Indeed, after some attempts, the right property came out: proportionality. But the number of correct answers in the grid of the results appeared to be fewer than expected. The quick oral survey that $\mathrm{T}$ had carried out helped him in his interpretation of the data and in understanding what problems could have occurred. In particular, he realised that part of the wrong answers he saw in the common grid were not due to a mathematical misunderstanding or a conceptual error. They were probably due to a spelling error in typing the answer (proportionnalité in French).

From the case discussed above, we can detect two of T's emergent techniques to foster formative assessment in the classroom:

- discussing the solution of a student;

- making a survey in the classroom.

Indeed, both techniques were employed by the teacher with the purpose of collecting students' conceptions, proposals or responses, and commenting them with the class. In discussing the solution of a classmate, the teacher can elicit students' difficulties and students can position themselves with respect to the class level of understanding of the idea and to the target learning goals.

$\mathrm{T}$ explored for the first time the possibilities offered by the connected classroom technology in supporting these techniques. As a result of his orchestration choices, evidence of students' achievements was elicited and interpreted, but the process of exploiting them was both complicated and time-consuming. Indeed, there were moments when technology could have helped, but the teacher did not take advantage of it. For example, if every student had worked on his/her tablet, Student1 could have shared his screen with his classmates in order to explain his reasoning. Thus, the teacher could have extended the milieu to include the students' actual tablet productions.

We note that the process of instrumental genesis had begun for the students, who used the tablet to record their answers and send them to the teacher, by following the instructions appearing on their tablets in the interface of NetSupport School. At this initial stage, they did not feel familiar enough with the artefact to use it for other purposes, namely for writing, exploring constructions or doing calculations. Students preferred to use their notebook, which they were used to.

Thus, we can state that they were in a phase of instrumentation, where the artefacts (i.e., tablets and software) were acting on the subjects, influencing the development of their schemes of use. Students were appropriating the schemes of use that the teacher had decided to exploit in the network of tablets. The teacher, in turn, had begun his process of instrumental genesis to appropriate the use of the connected classroom technologies in his classroom. In this initial phase, he tested the technical properties of the artefacts (i.e., the network of tablets and the student response system), limiting their use to a means of communication with the students. Hence, we can affirm that the teacher also, trying to discover the functionalities of the connected classroom technologies, was in a phase of instrumentation, where the artefacts acted on him resulting in certain schemes of use.

A preliminary analysis and the a posteriori discussion with the teacher concerning this particular lesson allowed us to highlight the possible expansions of the milieu, 

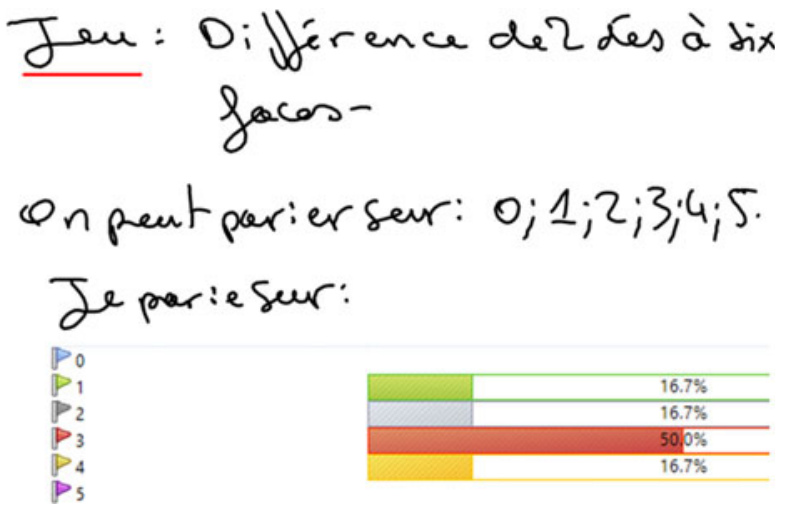

Fig. 5 Task and collected initial data: Game: Difference of 2 six-faced dice. / We can bet on: $0 ; 1 ; 2 ; 3 ; 4 ; 5$. / I bet on: / [histogram]

related to the use of technology, in order to improve what had been done and to try out some new techniques.

\section{Next Classroom Observations: February and April 2015}

When we visited the same tablet classroom again, 2 months later, we observed a remarkable evolution in T's appropriation of the connected classroom technologies and in his didactic practices with them, especially with respect to formative assessment. At the same time, students seemed very confident with the use of tablets and software. We attended one lesson concerning the first introduction of the notion of probability, ${ }^{2}$ which aimed to define the probability of an elementary event in a sample space.

T proposed to the students to play a game: betting on the difference of two dice with six faces. The first of T's orchestration choices was creating a survey via the tablet to collect the students' initial perceptions (see Fig. 5).

Afterwards, T led his students to an a-didactic phase, where they worked in small groups to explore the problem (Fig. 6). Each member of the group was required to work on his/her own tablet, with the common aim of coming to a shared conclusion: on which result they will bet and why?

In a third phase, $\mathrm{T}$ collected one response for each group, by means of making tablet screen shots. He displayed the different proposals on the IWB, commenting on and discussing them with the class. The tablets were blocked during this central phase of the lesson, since the teacher wanted to have the complete attention of the students (see Fig. 7).

In the last phase, $\mathrm{T}$ got to the institutionalisation of the definition of probability, starting from students' responses available at the IWB (see Fig. 8, as an example): this strategy allowed him to validate students' work, in a perspective of formative assessment within the learning process.

Connected classroom technologies played a relevant role in the way the teacher orchestrated the classroom activity and guided the lesson. NetSupport School permitted him to collect in real-time the students' work, to foster discussion and debate in the classroom and to use such data to construct the lesson notes at the whiteboard.

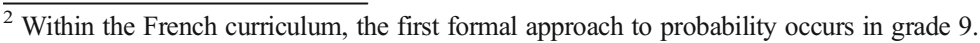




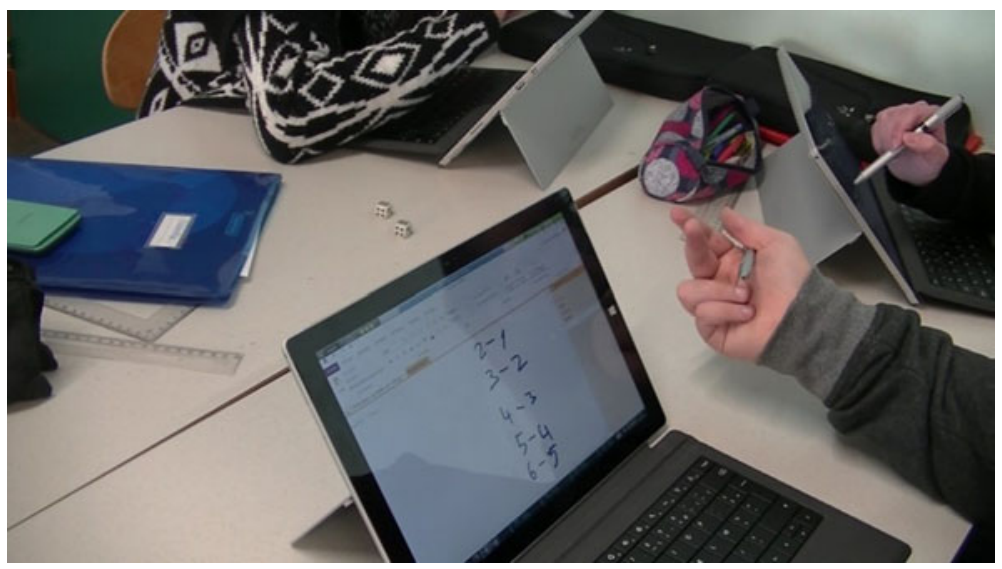

Fig. 6 Configuration of the work in groups with tablets

Moreover, technology allowed the teacher to enrich the students' milieu by sharing the different proposals and ideas produced by the students in the a-didactic phase.

At this stage in the year, it is possible to highlight an evolution of the teacher's instrumental genesis, where the stabilisation of the schemes of use of the tablets network leads to a recognisable practice of formative assessment with technology: making a survey in order to collect students' initial knowledge or conceptions through the student response system; devolving a problem to students and asking them to write their answers on the tablet in order to share them with the class; discussing the proposals of one (or several) student(s) with the class by displaying them on the IWB. The techniques to foster formative assessment in the classroom which were

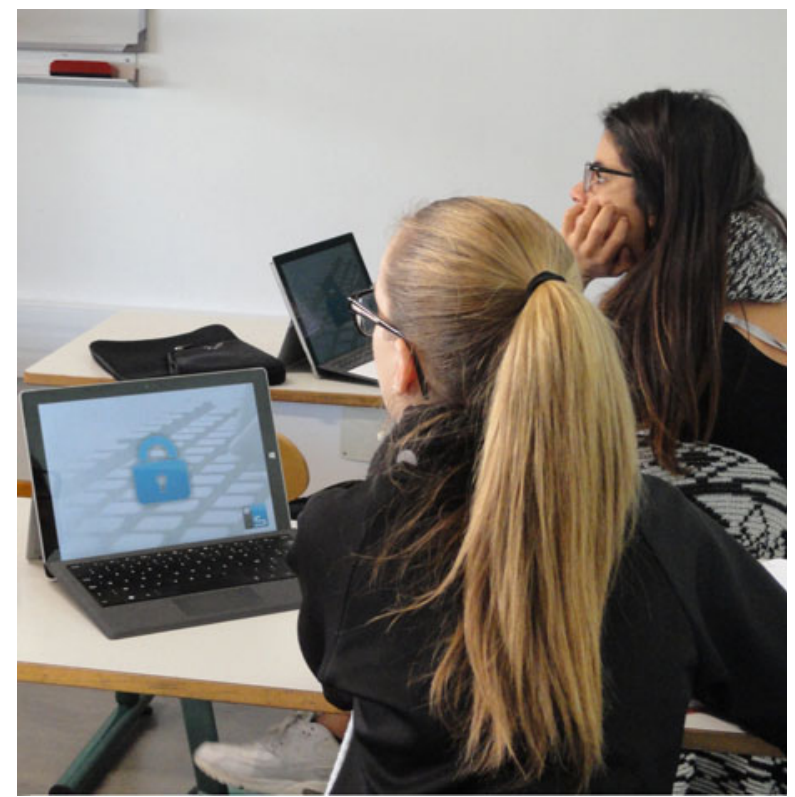

Fig. 7 Tablets are blocked during discussion to ensure the students' attention 


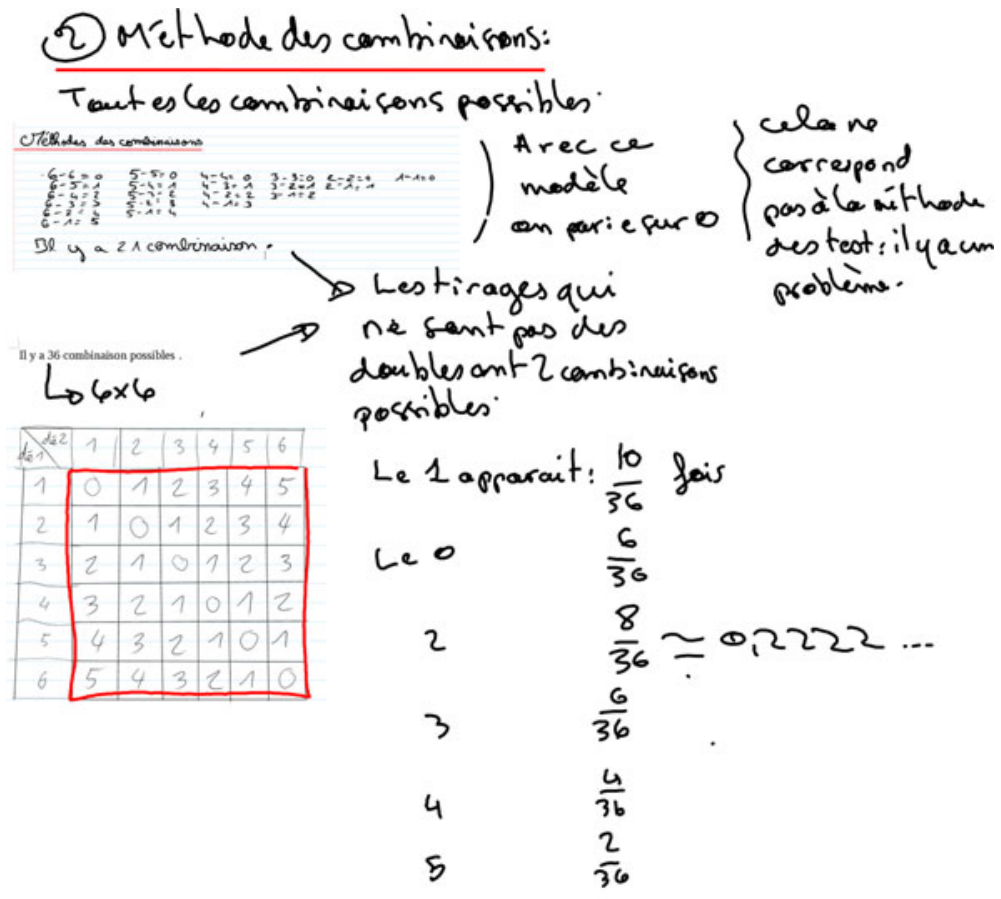

\section{La probabilite d'a parition du 1 est $\frac{10}{36}$, envicon 0,277.}

Fig. 8 Lesson notes on the IWB using the students' responses as a basis

observed in November are now inserted into a global process integrating the communication properties of technology.

Data from our third observation, almost at the end of the school year, confirmed the evolution of T's practices and the deeper integration of connected classroom technologies into his strategies to collect data, to interpret them and to exploit them in an efficient way. The orchestration choices made by the teacher during the observed lesson about linear functions were a refinement of his teaching practices that we observed in February and that we can consider as having become stable.

Specifically, T made a survey to understand if students had learnt how to recognise a linear function. Furthermore, he commented on the students' responses, giving feedback on them, with an explanation when the answer was wrong and some additional information when needed (see Fig. 9).

The second part of the lesson involved the discovery of the role of the coefficients $a$ and $b$ in the functional expression $f(x)=a x+b$. T orchestrated the students' work: they wrote their ideas on their own tablet; he made some screen shots of their work and he projected them on the IWB, amending their conjectures and adding information. As before, this data collection became part of the notes for the lesson. The students' milieu was highly enriched by this teaching practice, because they had the possibility of getting feedback about their personal response or of relying on the others' ideas for improving their own learning. 


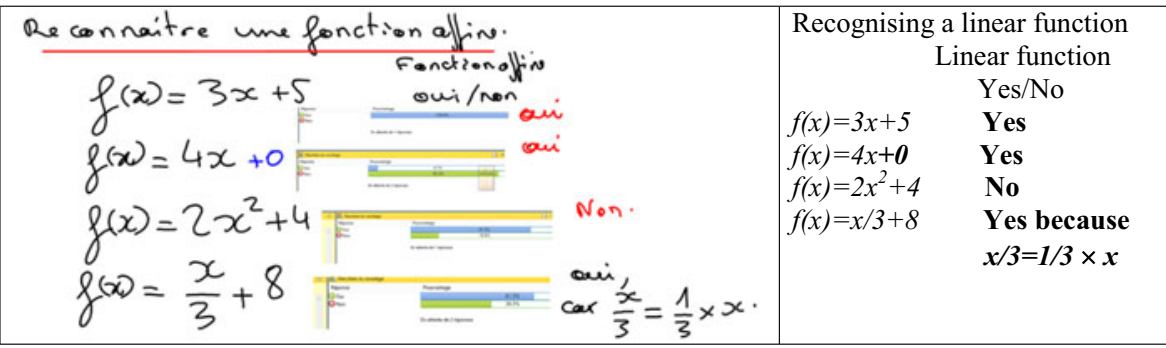

Fig. 9 Exploitation of data from a classroom survey (translation on the right)

\section{Discussion and Conclusion}

Our study aimed to identify elements of efficient formative assessment practice with the support of technology. Observing the teachers' usual employment of technology in the classroom can enable us to support them more effectively in developing and adapting their formative assessment practices and to interpret possible changes in their usual techniques. The proposed case study analysis gives us some valuable indications about how teachers can process data from students using technology and, consequently, how they can use this data to inform their teaching. The comparison between the later learning sequences (on probability and linear functions) with the early lesson about the geometry of the circle showed a significant modification in the teacher's practices and the essential support of technology.

One general characteristic of this particular teacher- but that was also observed with all the teachers participating in the project - is that, before the collaborative work with researchers, formative assessment seemed present in the teachers' intentions, but actually was not entirely implemented in the classroom. Typically, the teachers implemented some parts of the formative assessment process, but not formative assessment as a whole.

Coming back to our research questions in line with the FaSMEd project, this case study shows that the formative assessment strategies present in the teacher's intentions were reinforced and augmented by the use of technology. In this article, we have shown how one particular teacher processes formative assessment data from students using the functionalities of networked tablets. But also, we note that this teacher's formative assessment process includes modifications of his teaching according both to an immediate and to a post-reflection analysis.

At the end of the first school year with tablets, connected classroom technologies (in this specific case, NetSupport School and its student response system) were integrated into the formative assessment practices of the observed teacher. In a meeting with all the teachers involved in the FaSMEd project at the end of the year, we asked each teacher to present his/her experience, specifying at which moments and for which purposes technology had been useful.

When $\mathrm{T}$ talked about his use of the network of tablets for discussing students' proposals and making surveys, he commented: "Since I use NetSupport School in the classroom, I can detect difficulties and treat them more effectively, intervening for the whole class or individually. [...] I had the pleasure of discovering formative assessment. [...] I will never go back". In the examples discussed, the teacher's orchestration choice, one in which each student should work on his/her own tablet, facilitated access 
to students' work and personalised interventions about their responses. The teacher's orchestration skill of sharing tablet screenshots at the IWB allowed him to compare and discuss students' ideas, in order to enrich the milieu by means of public feedback on students' work.

Therefore, technology supports the process of collection-interpretation-exploitation of the evidence of student achievement, making the teaching techniques of discussing a student's response and holding a survey in the classroom more efficient. In particular, such strategies become effective when technology allows the teacher not only to collect data and to analyse it more quickly, but also to exploit it, with the specific aim of enriching the students' milieu. For this teacher, the technology can be seen to amplify his teaching intentions and facilitate his understanding of students' knowledge construction. The teacher's orchestration skill was the result of his appropriation of the schemes of use of connected classroom technology, in relation to formative assessment. Such competences are built jointly with the students' instrumental genesis.

This study echoes results reported in the literature (e.g., Stroup et al. 2002; Walling 2014; Clark-Wilson 2010), by showing that the teacher's appropriation of connected classroom technology needs time and can deeply influence the students' appropriation of technology, as well as students' construction of mathematical knowledge. Nonetheless, this article adds something both to the research about connectivity in the classroom and to those studies about formative assessment, pieces that that literature often treats separately. Ours investigates these two important themes jointly, and highlights strongly the benefits for teaching practice when connected classroom technology is used with the specific aim of assessing students' competences in a formative way.

In the interviews at the end of the school year, some students declared that, thanks to the student response system, they felt that the teacher knew better where they were in their learning path. One student said, "He has that thing, the questions-answers, and then he sees if there are many of us who achieve success or not". It is clearly a perception related to the teacher's improved view of the class as a whole. An interesting further development of this study will focus on the possibilities offered by connected classroom technologies to enhance the teacher's understanding of each individual student's progress and learning needs. This may help us gain insight into the formative assessment process supported by technology from the students' perspective.

Acknowledgments The research leading to these results reported in this article has received funding from the European Community's Seventh Framework Programme fp7/2007-2013, under grant agreement No 612337.

\section{References}

Aldon, G. (2014). Didactic incidents: a way to improve the professional development of mathematics teachers. In A. Clark-Wilson, O. Robutti, \& N. Sinclair (Eds.), The mathematics teacher in the digital era: an international perspective on technology-focused professional development (pp. 319-343). Dordrecht, NL: Springer. 
Aldon, G., Artigue, M., Bardini, C., et al. (2008). Nouvel environnement technologique, nouvelles ressources, nouveaux modes de travail: le projet e-CoLab (expérimentation collaborative de laboratoires mathématiques). Repères-IREM, 72, 51-78.

Artigue, M. (2002). Learning mathematics in a CAS environment: the genesis of a reflection about instrumentation and the dialectics between technical and conceptual work. International Journal of Computers for Mathematical Learning, 7(3), 245-274.

Black, P., \& Wiliam, D. (2009). Developing the theory of formative assessment. Educational Assessment, Evaluation and Accountability, 21(1), 5-31.

Black, P., Harrison, C., Lee, C., Marshall, B., \& Wiliam, D. (2003). Assessment for learning: putting it into practice. Buckingham, UK: Open University Press.

Borman, D., \& Sleigh, A. (2011). An evaluation of the use of interactive approaches and integrated on-line resources. Teaching Mathematics and its Applications, 30(4), 166-177.

Brousseau, G. (1997). Theory of didactical situations in mathematics: didactique des mathématiques 19701990. Dordrecht, NL: Kluwer Academic Publishers.

Clark-Wilson, A. (2010). Emergent pedagogies and the changing role of the teacher in the TI-nspire navigatornetworked mathematics classroom. ZDM - The International Journal on Mathematics Education, 42(7), $747-761$.

Hattie, J. (2009). Visible learning: a synthesis of over 800 meta-analyses relating to achievement. Abingdon, UK: Routledge.

Lawson, D. (1999). Formative assessment using computer-aided assessment. Teaching Mathematics and its Applications, 18(4), 155-158.

Looi, C.-K., \& Chen, W. (2010). Community-based individual knowledge construction in the classroom: a process-oriented account. Journal of Computer-Assisted Learning, 26(3), 202-213.

Pape, S., Irving, K., Owens, D., Boscardin, C., Sanalan, V., Abrahamson, L., Kaya, S., Shin, H., \& Silver, D. (2013). Classroom connectivity in algebra I classrooms: results of a randomized control trial. Effective Education, 4(2), 169-189.

Rabardel, P. (1995). Les hommes et les technologies: approche cognitive des instruments contemporains. Paris, FR: Armand Colin (https://hal.archives-ouvertes.fr/hal-01017462/document).

Roschelle, J., \& Pea, R. (2002). A walk on the WILD side: how wireless handhelds may change computersupported collaborative learning. International Journal of Cognition and Technology, 1(1), 145-168 (https://telearn.archives-ouvertes.fr/hal-00190615).

Scardamalia, M., \& Bereiter, C. (2006). Knowledge building: theory, pedagogy, and technology. In K. Sawyer (Ed.), Cambridge handbook of the learning sciences (pp. 97-118). Cambridge, UK: Cambridge University Press.

Stroup, W., Kaput, J., Ares, N., Wilensky, U., Hegedus, S., Roschelle, J., Mack, A., Davis, S., \& Hurford, A. (2002). The nature and future of classroom connectivity: the dialectics of mathematics in the social space. In D. Mewborn, P. Sztajn, D. White, H. Wiegel, H. Bryant, \& K. Nooney (Eds.), Proceedings of the 24th PME-NA conference (Vol. 1, pp. 195-213). Columbus, OH: ERIC Clearinghouse for Science, Mathematics, and Environmental Education.

Swan, M. (2014). Design research in mathematics education. In S. Lerman (Ed.), Encyclopedia of mathematics education (pp. 148-151). Dordrecht, NL: Springer.

Taras, M. (2012). Where is the theory in assessment for learning? Online Educational Research Journal. pp. 11 (http://www.oerj.org/View?action=viewPDF\&paper=76).

Trouche, L. (2004). Managing the complexity of human/machine interactions in computerized learning environments: guiding students' command process through instrumental orchestrations. International Journal of Computers for Mathematical Learning, 9(3), 281-307.

Walling, D. (2014). Designing learning for tablet classrooms: innovations in instruction. Cham, CH: Springer. 